\title{
O DIÁRIO ESCONDIDO DA SERAFINA: A HIPERTEXTUALIDADE NA LITERATURA INFANTIL CONTEMPORÂNEA
}

\author{
Elaine Cristina da Silva Martins* \\ Adair de Aguiar Neitzel* \\ Cláudia Suéli Weiss ${ }^{* * *}$
}

\begin{abstract}
RESUMO: Este artigo tem como objetivo analisar as características hipertextuais na literatura infantil. Como corpus de análise, foi escolhido o livro O diário escondido da Serafina. Partiu-se do conceito desenvolvido por Neitzel (2009) de que uma obra hipertextual é aquela que apresenta quatro princípios que cooperam para a sua textualidade múltipla: reversibilidade, rede e nós, interação e engastes. Como resultado, indica-se que os aspectos gráficos (layout) do livro analisado permitem a quebra da linearidade do texto e colaboram para ampliar as possibilidades de entrada do leitor nas suas malhas. Além disso, a grande quantidade de textos espraiados no interior da narrativa também auxilia a produtividade, de modo a propor diálogos entre diversos textos, além de apontar para a construção de um texto plural.
\end{abstract}

Palavras-chave: Hipertexto. Formação de leitores. Leitura do literário. Hipertextualidade.

\section{Introdução 1}

Que porto pode acolhê-lo com maior segurança que uma grande biblioteca? Certamente haverá uma na cidade da qual partiu e à qual retorna depois de uma volta ao mundo de um livro a outro [...].

Ítalo Calvino

Conta a história, não muito remota, que, no circuito cultural, a biblioteca fechavase em si e tinha a função de proteção e de preservação do patrimônio textual. Logo, tinham acesso aos livros os mais esclarecidos que sabiam como lidar com esse patrimônio. Além dos cuidados com o livro, sabiam comportar-se e manter o

\footnotetext{
*Universidade do Vale do Itajaí, Itajaí,Brasil. elainemartinsitj@hotmail.com.

** Universidade do Vale do Itajaí, Itajaí,Brasil. neitzel@univali.br.

*** Universidade do Vale do Itajaí, Itajaí,Brasil. claudia.du@yahoo.com.br.

${ }^{1}$ Esta pesquisa contou com a colaboração da bolsista de iniciação científica Ana Maria Cordeiro (UNIVALI).
}

\section{(c) BY-NC-ND}

Esta obra está licenciada com uma licença Creative Commons. 
devido silêncio exigido em uma biblioteca. No fragmento da epígrafe, Calvino (1999, p. 256) suscita questionamentos contemporâneos tais quais: "Será a biblioteca um porto seguro?"; "Será povoada por livros que acomodam?"; "O livro é um veículo ou uma passagem?". O autor evoca o convívio dos contrários, quando ele traz à baila a biblioteca e remete-nos, momentaneamente, a um lugar sisudo, silencioso e inerte, e, em seguida, sugere que ela é povoada de livros e estes são veículo e passagem para o deslocamento no tempo e no espaço.

Este artigo tem como objetivo geral analisar os elementos hipertextuais que se apresentam e se relacionam na composição da narrativa mirim contemporânea, especificamente, na obra O Diário escondido da Serafina. Percebemos que, após trinta anos de discussão sobre a formação de leitores, sobre a natureza da literatura e suas funções, presenciamos que ela começa a provocar abalo nas atuais estruturas escolares e passa a ser trabalhada pela via artística e estética, visando à formação de leitores mais sensíveis e críticos. Observamos, por meio desta pesquisa, que o mundo contemporâneo traz em seu bojo uma nova criança e um novo livro. Mas, como esse livro se apresenta à criança? Partimos do conceito de hipertextualidade, desenvolvido por Neitzel (2009), para analisar a obra selecionada e identificar se ela traz marcas hipertextuais. Para a autora, as narrativas hipertextuais são aquelas que obedecem a quatro princípios que cooperam para a efetivação de uma obra hipertextual, a saber:

- constitui-se pela reversibilidade;

- é um composto de rede e nós;

- oferece ao leitor mais possibilidades de interação;

- constitui-se por uma sequência de engastes.

Neitzel (2009) potencializa o hipertexto como um espaço duplo de escrita e de leitura, o que significa que o leitor figura como co-autor, tendo em vista que a obra não está pronta, mas foi organizada de forma a concretizar-se no ato de leitura, por meio de jogos-montagem, pois a narrativa se apresenta fragmentada. No exercício de conectar os fragmentos, o leitor envolve-se em uma leitura mais 
dinâmica, com outras possibilidades de ressignificação da obra. Desse modo, a abertura e o dinamismo, segundo Eco,

[...] consistem em tornar-se disponível a várias integrações, complementos produtivos concretos, canalizando-os a priori para o jogo de uma vitalidade estrutural que a obra possui, embora inacabada, e que parece válida também em vista de resultados diversos e múltiplos. (ECO, 2012, p. 63).

O diário escondido da Serafina é uma obra que estabelece um intenso diálogo com outros textos, causando rupturas na narrativa e provocando uma multilinearidade, que, segundo Neitzel (2009, p. 13), é o que mantém a reversibilidade do texto, o qual é "[...] fragmentado em blocos, e esta ação oferece ao texto vários prolongamentos desfocados, atemporais, bifurcações que constroem uma produção descontínua". O leitor opera um devir entre os fragmentos - sejam estes textuais ou visuais. Ele faz, assim, uma leitura reversível, com entradas e saídas bifurcadas, descontínuas, desfocadas. Ou seja: formas de um texto diverso que se apresenta multilinearmente.

Ao explorar vários recursos de comunicação com o leitor - seja por meio da palavra, da imagem, do layout (que implica a exploração de dobradoras) ou da citação direta e indireta, ou ainda da alusão - , o livro propõe a ideia de um texto construído em rede com conexões múltiplas, convidando-nos a percebê-lo como resultado de uma produção coletiva. Trata-se de um texto que se constrói em relação com o outro. O escritor propõe uma narrativa para o leitor que deve saltar entre os elementos que dinamizam a escrita, ou seja, outros textos são colocados em articulação com a obra. Entendemos que os encontros ou desencontros promovidos pelos elementos hipertextuais que articulam uma trama em rede também instituem os nós conectivos dessa rede textual. Nós que não atam, mas encostam, promovem encontros e tendem a ampliar a significação da obra.

A multiplicidade de textos espraiados no interior da narrativa também auxilia a produtividade, de modo a propor diálogos entre diversos textos e apontando para a construção de um texto plural, em rede, o qual promove mais possibilidades de 
interação por meio da montagem. Este articula os elementos linguísticos espraiados, garantindo a coexistência e a simultaneidade de ações, tempos e espaços na produção de sentidos. Tal composição textual em rede faz alusão a outros textos, e é marcada pelo processo criativo do escritor, sugerindo uma leitura permeada pela interconectividade de um verbete que, às vezes, leva a outro, de modo a imprimir uma sequência de engastes.

A literatura contemporânea traz em sua constituição elementos hipertextuais que desacomodam e rompem com as estruturas. Buscamos, assim, sinalizar, nesta pesquisa, que a literatura infantil vem se aproximando das narrativas hipertextuais ao se pautar por algumas experimentações na forma e no conteúdo que visam a ampliar a significação por parte do leitor e expandir a leitura para além das páginas do livro, de modo a conferir um valor estético à obra. Nessa perspectiva, este artigo sublinha aspectos como a importância de um acervo literário que desafie o leitor mirim à leitura, para, assim, estruturar-se um trabalho de qualidade estética na formação literária infantil, com vistas a uma valorização do leitor mirim que pode emocionar-se com as descobertas. Para Neitzel (2009), a hipertextualidade de uma obra só se concretiza quando o leitor não reduz as relações da obra a uma única interpretação tida como verdadeira.

\section{Dobras e desdobras, frestas para espiar sonhos, amigos e livros em 0 diário escondido da Serafina}

Publicado em 1996 pela editora Ática, o livro O Diário Escondido da Serafina é da autora Cristina Porto e ilustrado por Michele lacocca. A autora comenta na capa do livro que ele é um presente à personagem Serafina, por sua capacidade inventiva para brincadeiras e presentes originais. A ilustradora aproveitou o traço bem-humorado de Serafina para criar uma personagem menina, inquieta e criativa. É nesse contexto que segue a história. A menina cria esconderijos que a permitem, de forma diversa e divertida, deslocar-se entre as folhas e as linhas do texto, da narrativa para as dobras, das dobras para a narrativa, em um ziguezague dinâmico e interativo. De certa forma, essa estrutura textual 
apresenta-se como um jogo - Serafina, nessa brincadeira de esconderijos secretos, revela seus sonhos, seus amigos, seus livros preferidos, bem como sua identidade de menina aventureira e criativa.

$\mathrm{Na}$ obra em análise, o layout e a ilustração tendem a potencializar a narrativa e permitir ao leitor fruir a leitura e produzir sentido ao que se vê/lê de forma dinâmica e divertida. O layout é composto por uma folha retangular branca. A numeração encontra-se no meio da folha. Há uma margem pré-definida. Em algumas páginas, dobras e desenhos infantis extrapolam esse espaço, colocando em evidencia certo movimento, quebrando a estática organização da página.

O texto está centralizado na página e os caracteres nele encontrados estão na cor preta, com a mesma fonte e tamanho. O texto não é justificado, o que dá a sensação de diário escrito artesanalmente. Ainda com relação aos caracteres, encontramos nos títulos letras coloridas, tremidas, com fontes e tamanhos diferenciados. Nesse caso, é possível observar que o próprio texto se constitui como parte da ilustração, ao considerar que as palavras são imagens que representam algo. Julga-se que a cada página o leitor sente-se mais convidado a abrir o livro e a operar um movimento dinâmico de leitura por meio dos diversos elementos contidos no livro.

Quanto à ilustração, as dobras que aparecem ao longo da narrativa, na cor amarela, contrastando com a cor branca da folha, sugerem um instigante e divertido jogo, com combinatórias entre texto e ilustração. Entendemos que as dobras instauram esse jogo na leitura por meio do engaste, interconectividade entre a narrativa e ilustração, entre um verbete e outro, ampliando a significação desse texto que se constrói em rede e que articula palavras e ilustrações. As dobras são diferentes, aparecem na ponta da folha, meia página, duas ou mais folhas e guardam verdadeiros tesouros para avançar no jogo, como demonstrado na Fig. 1 a seguir. 
Figura 1 - Várias dobras

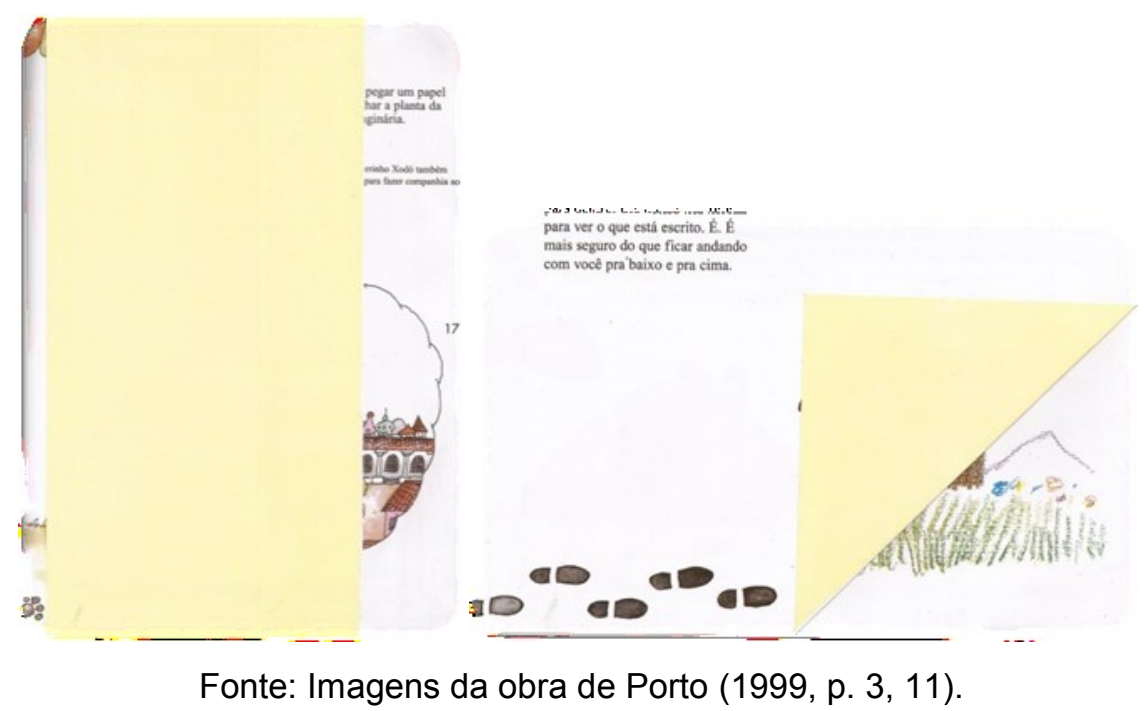

As ilustrações trazem à tona um grande número de desenhos infantis, recortes e colagens em diferentes formas, cartões; remonta, assim, a um diário infantil. Essa construção literária aproxima-se da criança leitora na medida em que Serafina utiliza o diário íntimo, pois ela escreve sobre seu dia a dia de criança, confessa seus sentimentos e seus projetos como estratégia literária. Nesse contexto, a personagem mantém alguns diálogos com o diário à medida que vai escrevendo. Martins (2013) elucida-nos, em seu artigo intitulado Os perfis da literatura de introspecção: o diário em Virgílio Ferreira e a autoria na autoficção, que o diário, na qualidade de narrativa epistolar, é uma das técnicas literárias utilizadas para criar histórias com maior grau de proximidade da realidade. "O diário íntimo é um dos gêneros da literatura de introspecção, ele é de cunho subjetivo e confessional. Nele, estabelece-se o espaço da palavra de um sujeito, que se volta para si mesmo, num mergulho no eu, em busca de autoconhecimento através da análise das experiências vividas [...]" (MARTINS, 2013, p. 129, grifo do autor).

O diário constitui-se um espaço de livre expressão do escritor. O de Serafina é marcado por texto e ilustrações que registram seus pensamentos, seus sentimentos e suas lembranças. Na Fig. 2, a seguir, podemos ver alguns registros feitos por ela mesma ao longo do diário: 
Figura 2 - Desenhos infantis espraiados pelo livro

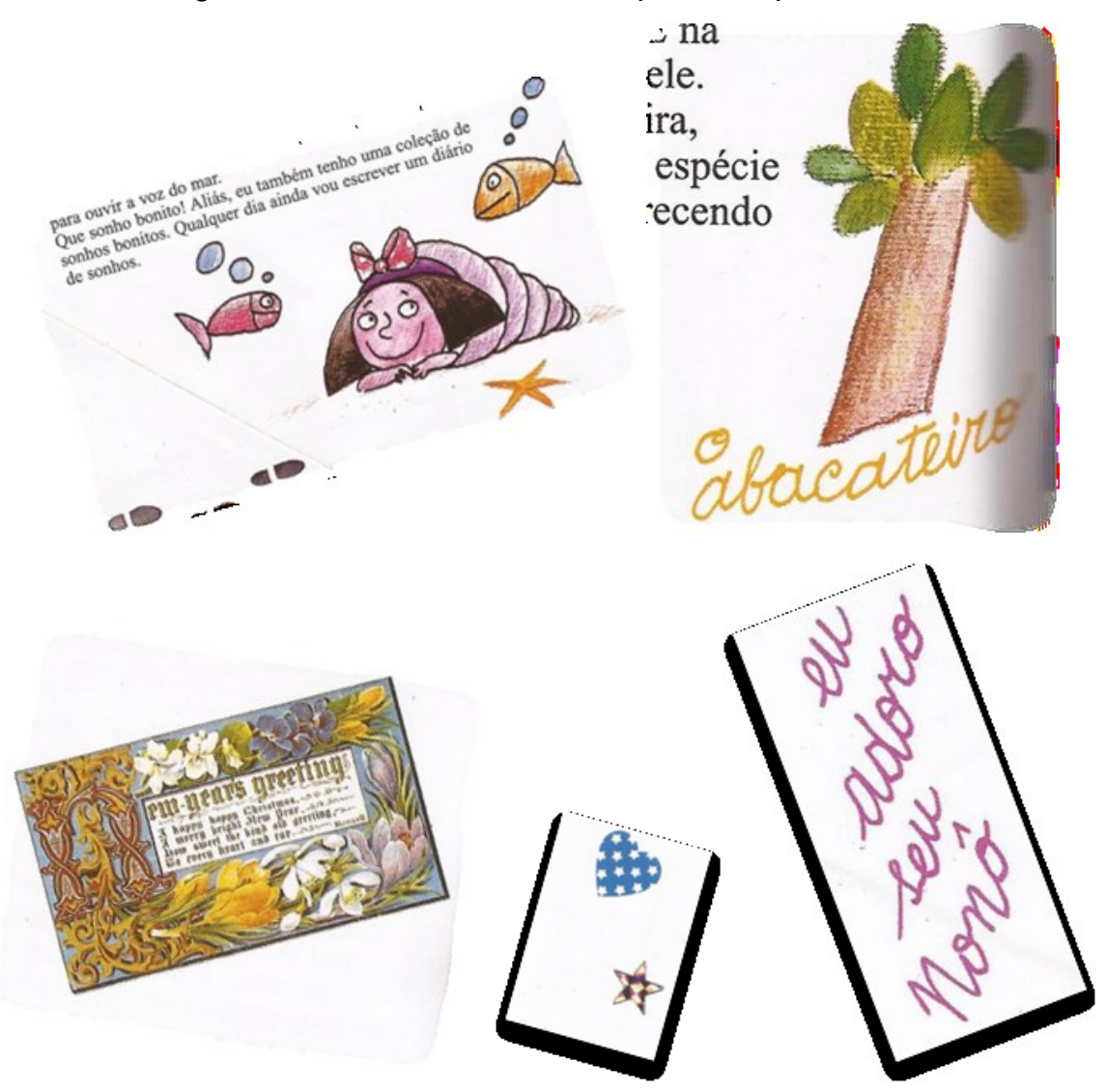

Fonte: Imagens da obra de Porto (1999, p. 2-34).

Outro destaque relevante nessa dinâmica ilustração são as dobras que ocupam mais de uma página. Praticamente no centro do livro, podemos encontrar duas folhas dobradas, com um enunciado colorido e letra caixa alta que ultrapassam a folha. Consideramos que esse experimento estético dilata o espaço textual, pois coloca em relevo a forma material do texto e a sua recepção. O leitor, diante dessas sugestivas dobras, tende a operar uma leitura com maior grau de interação com a obra. Assim, fica latente a possibilidade de o leitor percebê-la como objeto estético. Podemos enfatizar o pioneirismo desse livro na literatura infantil com relação à probabilidade de ele se constituir um objeto estético por uma construção narrativa perfurada por muitas estratégias textuais para a década de 1990, data da sua primeira edição. Hoje, essa exploração já é normal, mas, quando da sua publicação, era novidade. Na Fig. 3, a seguir, podemos ver uma dobra que rompe a linearidade do texto e propõe ao leitor um movimento físico para descobrir o segredo que está por trás da dobra. 
Figura 3 - Dobra que apresenta a CIDADINA, cidade imaginária de Serafina

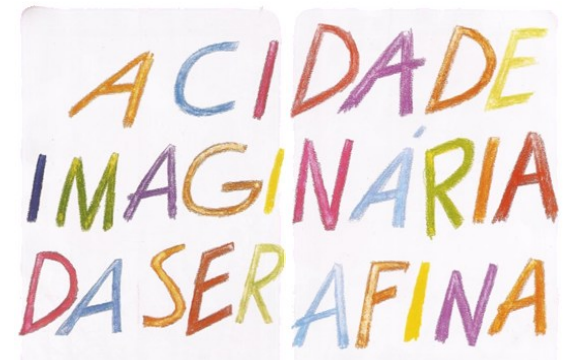

Fonte: Imagem da obra de Porto (1999, p. 18, 23).

Ao abrir essa brecha, o leitor depara-se com um cenário imaginado por Serafina ocupando três páginas. A quarta página encontra-se em branco e convida o leitor a participar da construção do livro por meio da frase: "Por que você não aproveita este espaço para continuar o desenho de Serafina?" (Fig. 4). Segundo Neitzel (2009), o leitor que se lança à "coautoria", ao penetrar no jogo de relações instaurado entre obra-leitor, "[...] intui que a obra ainda está por se fazer, que os estados de possibilidades de sua realização aguardam a intervenção do leitor, reafirmando a relação entre leitor e obra que a poética da obra aberta vem desenvolvendo" (NEITZEL, 2009, p. 121). Esta, portanto, é uma das oportunidades que o leitor tem de interagir com a obra, de interferir deixando o seu registro na medida em que constrói sentidos.

Figura 4 - Convite ao leitor

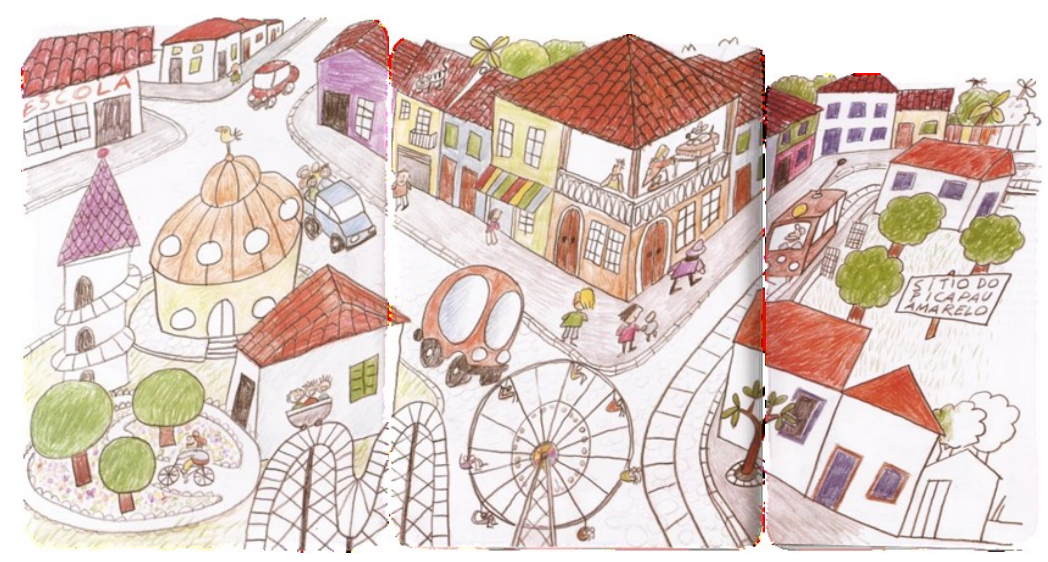




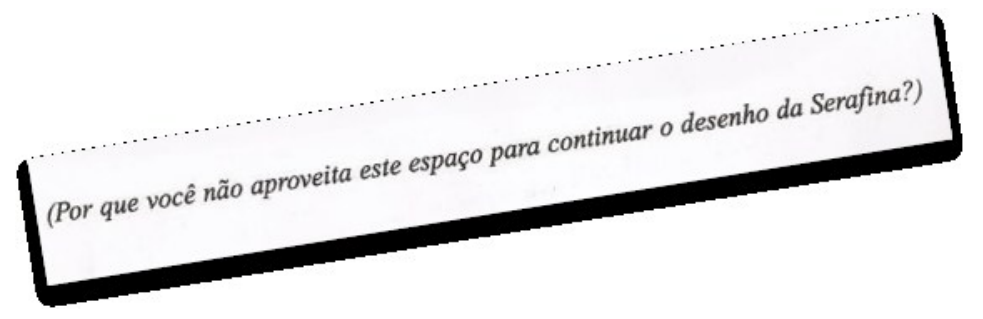

Fonte: Imagens da obra de Porto (1999, p. 19- 22).

Em outro momento, abre-se um calendário em mais de uma página (Fig. 5) e, junto, a possibilidade de o leitor inserir os aniversários que desejar. Essa atenção dada aos aspectos gráficos e estéticos de maneira criativa atrai o olhar do leitor e, por conseguinte, amplia a possibilidade de interação com o texto.

Figura 5 - Calendário

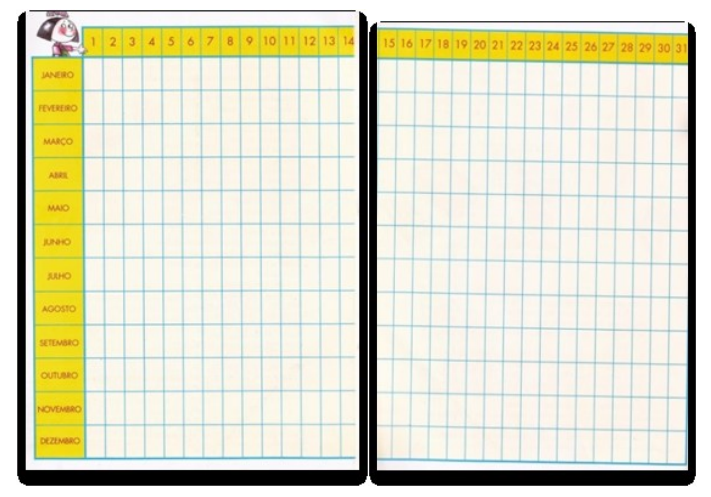

Fonte: Imagem da obra de Porto (1999, p. 31-32).

Do ponto de vista dos estudos da Gestalt do objeto, de Gomes Filho (2004), essas dobras podem ser consideradas como uma interferência na harmonia do objeto, identificada como ruído visual que, quando utilizado criativamente, tornase um "[...] ponto positivo e inteligente [...], sobretudo, além de atraente, chama a atenção do ponto de vista plástico e funcional". Como também pode dar um "[...] tom sofisticado de algo inusitado, que é, obviamente, uma coisa inesperada [...]" (GOMES FILHO, 2004, p. 102). Em um livro, dificilmente encontramos folhas dobradas. Geralmente, segue-se o padrão da folha reta sem dobraduras. ]Desse modo, tal estratégia visual tende a chamar a atenção do leitor, pois constitui um recurso funcional amplificado e interessante da composição. 
Dentre as estratégias visuais construídas para atrair, divertir e subverter a ordem no ato de ler, estão as linhas que, contínuas ou desalinhadas, encaminham o leitor a desvelar as dobras. As linhas sobre as quais estamos falando constituemse um fio que conduz ao enigma da narrativa, a surpresa do esconderijo. Elas se apresentam em forma de corações, em um pedaço de manta, alargamento, marcas de patas de animais, poça d'água, corda, nuvens, pegadas de gente etc. (Fig. 6). Inusitadamente na folha de rosto, encontramos pegadas de gente que passam pela página 2 e encerram ao encontrar a primeira dobra do livro na página 3. É o primeiro encontro do leitor com o tão sonhado esconderijo de Serafina. Segundo Gomes Filho (2004), a linha dá a sensação de direcionamento que, nesse caso, sugere apenas um dentre os caminhos que o leitor tem para ler a história que pode ser, também, só pelas dobras.

Figura 6 - Linhas que direcionam ao esconderijo

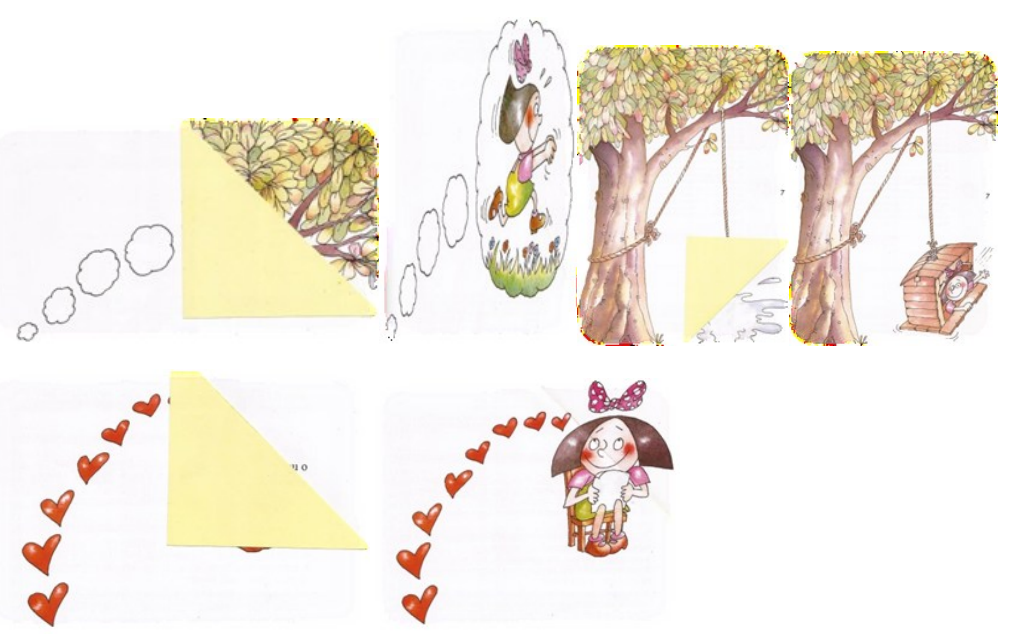

Fonte: Imagens da obra de Porto (1999, p. 5, 7, 41).

Tendo em vista que o jogo é um recurso que seduz pela sensação de liberdade e de escolha, esta narrativa-jogo, disseminada por Serafina, atrai a criança-leitora, que percorre as pistas dispersas ao longo das páginas e materializa o jogo à medida que aceita fazer parte do jogo-leitura instaurado pelas dobras, pelas linhas e por outras estratégias literárias. Essa participação do leitor na montagem dessa narrativa-jogo permite a interação e um movimento reversível de leitura. $O$ leitor pode operar um devir entre as pistas, um vai e volta divertido e talvez enigmático entre as dobras, linhas, elementos linguísticos e gêneros diversos da 
composição dessa malha textual. A história é de foro íntimo, mas abre espaço para o leitor participar da construção dos sentidos. Segundo Neitzel (2009), aceitar o jogo é uma forma de interagir com a obra.

A narrativa é composta por uma malha relacional intensa repleta de desvios que proporcionam diversos percursos de leitura. Recursos como as dobraduras, ao serem manuseados, revelam surpresas e instauram um tom lúdico na leitura da história. Este é um livro que se aproxima do livro-brinquedo e apresenta a literatura para a criança de forma mais lúdica. Com relação à ludicidade, seja a leitura seja o jogo, que sempre atraíram as pessoas, Neitzel (2009) pontua que há muito se fazem

[...] experiências combinatórias de letras, palavras e frases [...] Raymond Queneau, Cent mille milliards de poèmes e Un conte à votre façon, as de Hubert Lucot, como Legrand Graphe, ou as invenções de Georges Pérec, são escritores que exploram o lado lúdico das palavras e permitem ao leitor efetuar o percurso combinatório que desejar. (NEITZEL, 2009, p. 73).

Com relação ao enredo, a obra apresenta o diálogo da menina Serafina com o seu diário, em que ela conta sobre a criação de um esconderijo. Como exige o gênero epistolar, a narrativa é na primeira pessoa do singular, e a narradora, Serafina, faz a interlocução com o próprio diário e com outros espaços como o esconderijo. No decorrer da narrativa, ela o chama de Querido esconderijo e conversa com ele também. Martins (2013) nos elucida que a escrita diarística é um dos gêneros literários de cunho íntimo, confessional e subjetivo. Essa estratégia tende a aproximar-se do leitor porque "[...] está centrada no sujeito, fala de um eu que tenta desnudar a sua vida, se revelar, estabelecendo, assim, um elo íntimo entre autor e leitor" (MARTINS, 2013, p. 126, grifo do autor).

No livro O diário escondido da Serafina, deparamo-nos com uma escritura ficcional que abarca subjetividade, intimidade e confissões da personagem como parte da técnica do diário na qualidade de estratégia literária. A narrativa apresenta, de certa forma, a visão de mundo da personagem, "[...] iluminando certos pontos e deixando à sombra outros" (MARTINS, 2013, p. 128). Ao publicar 
a escrita íntima de um "diário", por exemplo, deve-se ter "[...] compromisso estético, deixando de ser um livre fluxo de desabafo para tornar-se uma obra literária [...]" (MARTINS, 2013, p. 128).

O diário, como gênero textual que está sendo discutido, nessa narrativa, traz um amálgama de linguagens artísticas, aproximando-se da realidade do leitor, por meio das literaturas infantis, da música, dos contos populares contados, bem como do espaço para dar continuidade na ilustração e do calendário a ser completado pelo leitor com suas informações particulares. Em específico, o diário analisado não possui data, mas possui como interlocutor o próprio diário, o esconderijo e o leitor. Nos estudos de Martins (2013), o leitor de diário é reconhecido como "contemporâneo da ação". A estrutura desse gênero aponta para um personagem que escreve subjetivamente enquanto vive, podendo-se reconhecer o tempo como presente.

No diário de Serafina, o autor foi capaz de entremear estratégias textuais que disparam pistas de diferentes percursos de leitura, as dobras, o P. S., as notas de rodapé e os outros contos - textos que se entrecruzam e imprimem a quebra da linearidade da narrativa.

Toda a narrativa do livro é escrita na forma de um diário. A cada página virada, há um novo dia, um novo texto, nova sequência. Portanto, não se trata de uma história linear que encadeia uma sequência de fatos e acontecimentos com iníciomeio-fim, dia após dia. Sua arquitetura textual faz alusão a uma média de dezoito textos (Fig. 7), perfurados por outras histórias, brincadeiras, sonhos, poemas, músicas, atribuindo, ao texto, uma estrutura multilinear. Forma-se, assim, uma espécie de rede por meio da qual passa todo o texto, na medida em que ilustração e textos diversos encontram-se, encostam-se, imprimem nós conectivos que permitem que a convivência das antíteses amplie a multiplicidade da malha textual. 
Figura 7 - Alusão a outros textos

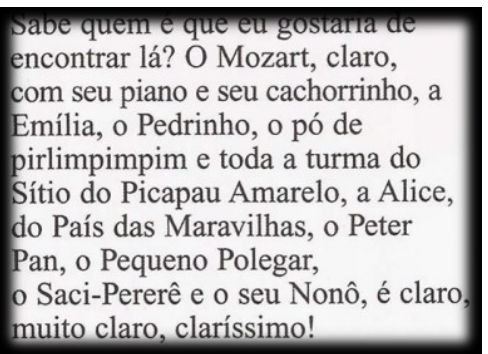

Fonte: Imagem da obra de Porto (1999, p. 17).

Do ponto de vista dos aspectos simbólicos, destacamos outras histórias da literatura infantil citadas, comentadas e ilustradas por Serafina na página 24 do livro (Fig. 8). Essa passagem evoca não só a multiplicação de histórias, mas também a amplificação da malha relacional que constitui essa história e a potência de uma obra aberta. Estamos falando de uma narrativa que se constrói em conexão com várias outras e que alça o leitor a vários espaços textuais diferentes. Se considerarmos que cada uma foi criada em determinada época, podemos afirmar que o leitor se lança a outros tempos.

Figura 8 - Outras histórias entremeadas na narrativa

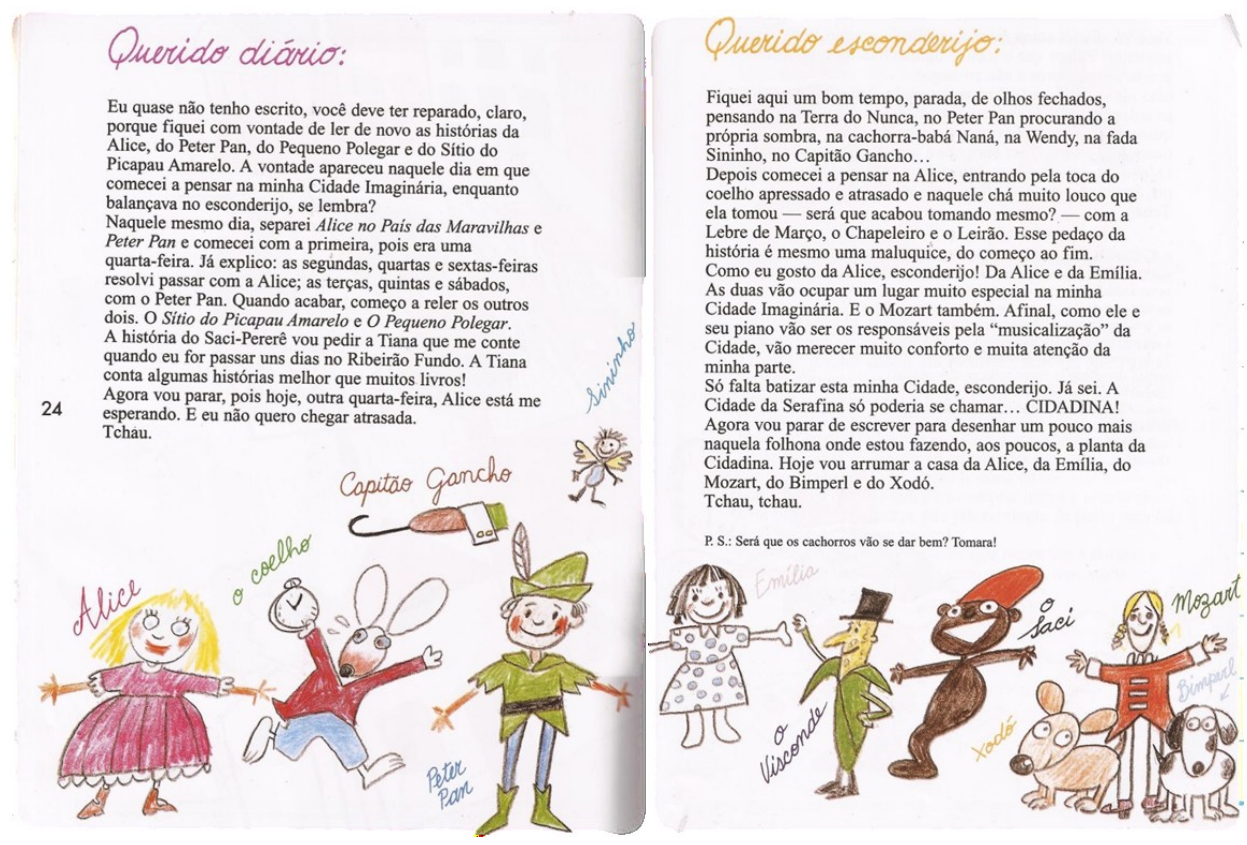

Fonte: Imagem da obra de Porto (1999, p. 24). 
O leitor infantil identifica-se com essa história porque a personagem possui, como toda a criança/jovem, o desejo de divagar pelo imaginário infantil, juntar pessoas e coisas em histórias inéditas e de sua autoria, sem preocupação com formalidades. Espontaneamente, Serafina expressa suas opiniões e seus sentimentos acerca do seu universo infantil.

A narrativa lança o leitor em um deslocamento no espaço textual e tende a "[...] transcender seus limites físicos para alcançar a leveza do espaço expansível do texto [...]" (WANDELLI, 2003, p. 220). Temos um exemplo desse movimento na página 8 , quando Serafina conta ao seu esconderijo que veio até ali só para chorar. Ela explica o tipo de choro ao término do texto. Mas, no final da folha, Serafina questiona o leitor: "Você notou que eu pulei um pedaço da página, não notou?" (PORTO, 1999, p. 8). Esse questionamento é capaz de suspender a leitura e colocar o leitor em um movimento de busca fora das páginas do livro para encontrar uma resposta. Portanto, trata-se de um texto que se expande para além do espaço da escrita.

Com relação à expansão do texto, a metalinguagem constitui-se uma estratégia que coloca em foco o debate a favor do livro, da leitura e da escrita. Encontramos histórias dentro de outras, ou uma ideia de livro dentro de outro, o que fortalece o potencial dessas estratégias para a formação do sujeito, mesmo que indiretamente. $\mathrm{Na}$ página 33 , Serafina apresenta ao seu diário o presente de aniversário que deu à sua amiga Julinha e explica que não se trata de um livrocaderno para ela escrever, mas é para ela pedir aos amigos que escrevam (Fig. 9). Serafina discute acerca da leitura e da escrita com certa magia e comprometimento com a comunicação e a expressão dos pensamentos e dos sentimentos: 
Figura 9 - Presente de aniversário

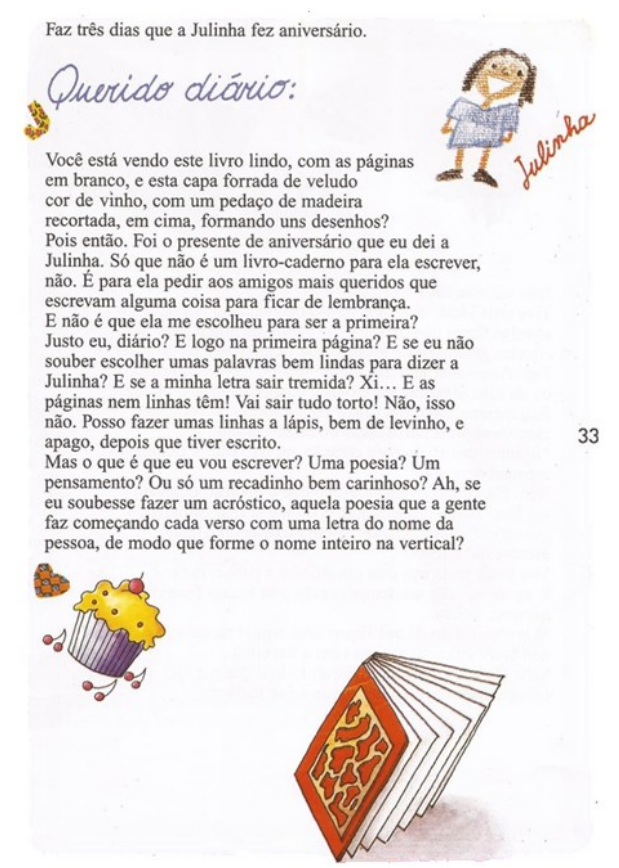

Fonte: Imagem da obra de Porto (1999, p. 33).

Com essa interpelação, o leitor para de ler, reflete sobre a indagação, coloca em suspensão o enredo para tentar montar o fragmento. Logo, questionamentos lançam o leitor em um movimento de reflexão sobre o próprio processo de escrita do literário, em um processo metatextual, de feitura do próprio livro, outro recurso que rompe com a linearidade do texto.

A cada página, um dia, um registro. A narrativa é construída em camadas. O leitor mais atento vai desdobrando não só as dobras da folha de papel, mas as inúmeras histórias (arte, literatura, música...) e personagens que Serafina vai, criativamente, apresentando. Constitui-se, então, uma leitura dinâmica. O leitor desliza ao longo das páginas do livro em um movimento fragmentado. Recheada de enigmas e surpresas, a narrativa propõe idas e vindas, entradas e saídas. Portanto, os assuntos encontram-se disseminados pelo texto, e, nesse sentido, a narrativa mostra-se fragmentada e interativa (NEITZEL, 2009).

Para ampliar os aspectos simbólicos do texto, os quais alargam a ambiguidade da obra e, consequentemente, a construção de sentidos por parte do leitor, Serafina, 
no decorrer da narrativa, cria palavras novas, como: Cidadina e Cadernofone. A primeira, ela criou para nomear sua cidade imaginária. Já a palavra Cadernofone, em uma nota de rodapé, indica que o significado será encontrado em outro livro seu denominado Serafina sem rotina. Essas palavras vêm a revitalizar o texto, levando o leitor a uma experiência linguística que mostra a provisoriedade da língua, a qual exige reflexão.

Para ampliar o sabor poético do texto - outra forma de revitalização da linguagem e de amplificação do campo semântico -, Serafina inicia o diário com uma parlenda recheada de aliterações, anáforas e metáforas. Ao longo do texto, duas versões são cotejadas (Fig. 10).

Figura 10 - Cultura popular e interculturalidade

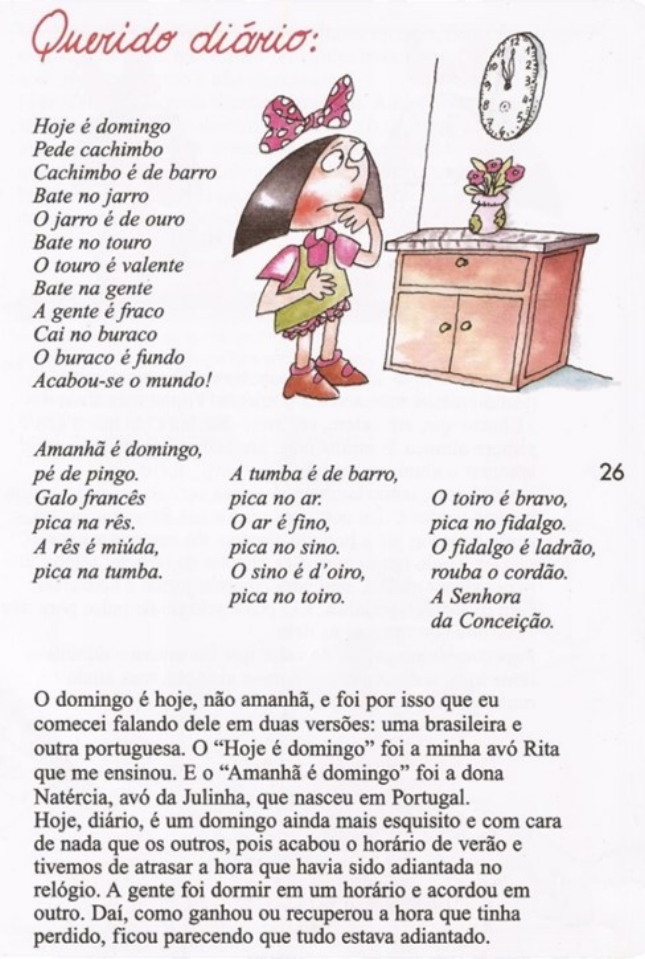

Fonte: Imagem da obra de Porto (1999, p. 26).

Para Ramos e Zanolla (2012), a inovação da literatura está na forma, seja pela estrutura seja pelo emprego da linguagem. A narrativa contemporânea, assim, tende a mobilizar intensamente o leitor. A narrativa em análise traz à tona 
novidades na forma de dizer. Ela apresenta um texto marcado por princípios que determinam uma obra hipertextual. Segundo Neitzel (2009), esses princípios estão amalgamados em um texto cheio de armadilhas e enigmas a serem perseguidos pelo leitor durante uma leitura dinâmica, de idas e vindas, entradas e saídas, sem hierarquização de partes ou blocos de temas. A obra mostra-se fragmentada e descontínua, ampliando a possibilidade de movimentação do leitor. Entre as dobras físicas e verbo-visuais que a obra propõe, cabe ao leitor montar os fragmentos espraiados pelo texto e dar sentido à obra mediante a criação pessoal, a suspensão dos fatos, a imprevisibilidade e a multiplicação dos significados. Distingue-se, portanto, por ser um texto não linear.

\section{Considerações finais}

Ao longo da análise do livro O diário escondido da Serafina, buscamos sinalizar como os aspectos de layout (gráficos), a escolha das palavras que compõem o estrato simbólico do texto, assim como os recursos que foram interpolados ao enredo da narrativa, colaboram para ampliar a produtividade do texto e as possibilidades de entrada do leitor nas suas malhas. Evidentemente, "[...] caberá ao leitor decidir sobre as possíveis relações que ele estabelecerá com outros textos, caberá a ele a decisão de abrir ou ignorar a arca de palimpsestos que sustenta o texto" (NEITZEL, 2009, p. 73).

A grande quantidade de textos dispersos no interior da narrativa aponta para a construção de um texto plural, o qual dá mais possibilidades para que o leitor modele a própria leitura. Esse texto composto como rede, do ponto de vista de Barthes (1997), é um texto ideal, cuja trama textual é múltipla e se entrelaça, "[...] este texto é uma galáxia de significantes, não uma estrutura de significados; não tem início; é reversível; nele penetramos por diversas entradas, sem que nenhuma possa ser considerada principal [...]" (BARTHES, 1997, p. 39-40).

Em se tratando de $O$ diário escondido da Serafina, tínhamos por objetivo responder: "Como este livro se apresenta à criança?", respaldadas pelos estudos de Neitzel (2009), sobre hipertextualidade. Esse livro possui um processo criativo 
balizado pelos elementos hipertextuais, os quais tendem a inovar a literatura infantil. É uma obra produtiva, que possibilita a multiplicação dos sentidos quando o leitor aceita o desafio e se lança à obra, ao ler os fragmentos em um movimento de leitura dinâmica e interativa.

Conforme os princípios identificados por Neitzel (2009), os textos literários hipertextuais são dinâmicos, interativos, coloridos, vibrantes e permitem maior participação do leitor na atividade de leitura. Expomos as características da literatura hipertextual, porque entendemos que, hoje, o livro de literatura infantil apresenta muitos recursos que são embriões para a hipertextualidade. O livro impresso, por mais linear que possa parecer, deu também um salto no que se refere à sua constituição como narrativa hipertextual. Em O diário escondido da Serafina, vemos um texto dinâmico, ou seja, que permite ao leitor movimentar-se em folhas dobradas, desenhos com traços infantis, recortes-colagens, linhas que indicam ludicamente percursos de leitura diversos. Enfim, uma escrita fragmentada que permite fazer leitura da direita para esquerda, de baixo para cima, compondo um processo mais interativo e exigindo do leitor não só movimento mental, mas também físico, na construção de significados.

O leitor precisa atravessar os nós na rede de relações que irá montar durante a leitura, que rompem com a linearidade do texto e com a realidade. Essa leitura provoca maior interação do leitor, ao passo que ele precisa ler de forma associativa e relacional, pois a sequência de engastes requer o entrelaçamento de todos os elementos da composição da narrativa, bem como acentuam a sua pluralidade. O leitor infere com mais flexibilidade o texto a partir das combinações semânticas pertinentes à construção textual, operando, dessa forma, engastes entre os signos, suas designações e suas referências.

Dessa forma, entendemos que essa obra é uma narrativa marcada por elementos hipertextuais, o que promove ao leitor também uma vivência estética. Do ponto de vista de Ramos e Zanolla (2012), as experiências de leitura enquanto vivência estética nas escolas são de caráter de urgência, pois podem significar momentos de prazer e de significação para todos, bem como revelar a eficácia da literatura Texto Digital, Florianópolis, Santa Catarina, Brasil, v. 11, n. 2, p. 91-110, jul./dez. 2015. ISSNe: 1807-9288. 
na formação de leitores quando se respeitam suas "[...] especificidades e as potencialidades do texto literário" (RAMOS; ZANOLLA, 2012, p. 258).

\section{O DIÁRIO ESCONDIDO DA SERAFINA: HIPERTEXTUALITY IN CONTEMPORARY CHILDREN'S LITERATURE}

RESUMO: This paper aims to analyze the hypertext features in children's literature. As analysis corpus, the book O diário escondido da Serafina (Serafina's hidden daily journal) was chosen. We started from the concept developed by Neitzel (2009) that a hypertext work is the one that presents four principles that work together for its multiple textuality: reversibility, network and knots, interaction and dovetail. As a result, we indicate that the graphic aspects (layout) of the analysed book allow the rupture of text linearity and collaborate to expand the reader's entry possibilities in the aspects of the text. In addition, the large amount of spread texts within the narrative also helps the productivity, proposing dialogs between various texts, pointing to the construction of a plural text.

Keywords: Hypertext. Reader education. Literary reading. Hypertextuality.

\section{Referências}

BARTHES, R. S/Z - uma análise da novela Sarrasine de Honoré de Balzac.

Tradução Léa Novaes. Rio de Janeiro: Nova Fronteira, 1997.

CALVINO, Í. Se um viajante numa noite de inverno. Tradução Nilson Moulin. São

Paulo: Companhia das letras, 1999.

ECO, U. Obra aberta: forma e indeterminação nas poéticas contemporâneas. 4. reimp. 9. ed. São Paulo: Perspectiva, 2012.

GOMES FILHO, J. Gestalt do objeto: sistema de leitura visual da forma. São Paulo: Escrituras, 2004. 
MARTINS, A. F. Os perfis da literatura de introspecção: o diário em Virgílio Ferreira e a autoria na autoficção. Revista Desassossego, São Paulo, n. 9, p. 125139, jun. 2013.

NEITZEL, A. de A. O jogo das construções hipertextuais. Florianópolis: Univali, 2009.

PORTO, C. O diário escondido de Serafina. 4. ed. São Paulo: Ática, 1999.

RAMOS, F. B.; ZANOLLA, T. Educação estética pela leitura literária.

Contrapontos, Itajaí, v. 12, n. 3, p. 250-258, set./dez. 2012.

Texto recebido em: 19/07/2015.

Texto aceito em: 29/10/2015. 